\title{
Anti-NGF therapy for bone cancer pain
}

The pain associated with bone cancer is often difficult to manage. It is relatively unresponsive to opioid therapy, which indicates that a neuropathic and/or tumorigenic component is involved. Nerve growth factor (NGF) is known to influence inflammatory and neuropathic pain, and anti-NGF therapy has been shown to alleviate both of these. Sevcik et al. have investigated the effects of a novel NGF-sequestering antibody on a mouse model of bone cancer, and propose two mechanisms for its painrelieving effects.

As expected, the antibody produced a significant decrease in ongoing and movement-evoked pain behaviours in the mouse model. However, the authors found that this pain decrease was not the result of changes in disease progression, sympathetic innervation or infiltration of macrophages to the bone.

They propose that anti-NGF therapy could have an impact on bone cancer pain in more ways than one. NGF is involved in many processes that increase nociceptive signalling, and reductions in several of these processes were seen in the mouse model in response to anti-NGF therapy. For example, the anti-NGF antibody reduced both the upregulation of dynorphin, which is involved in chronic pain, and the expression of activating transcription factor 3 (ATF3), which is upregulated in response to neuronal injury.

Furthermore, the anti-hyperalgesic effects of anti-NGF therapy could be partially attributed to the fact that almost all sensory innervation of bone is provided by nociceptors that express calcitonin generelated peptide (CGRP) and tyrosine kinase receptor $A$ (TrkA), which are susceptible to blockade by anti-NGF therapies.

The next step will be to investigate whether such therapies can produce safe and effective pain relief in humans.

Sarah Archibald

\section{(2) References and links}

ORIGINAL RESEARCH PAPER Sevcik, M. A. et al. AntiNGF therapy profoundly reduces bone cancer pain and the accompanying increase in markers of peripheral and centra sensitization. Pain 115, 128-141 (2003)

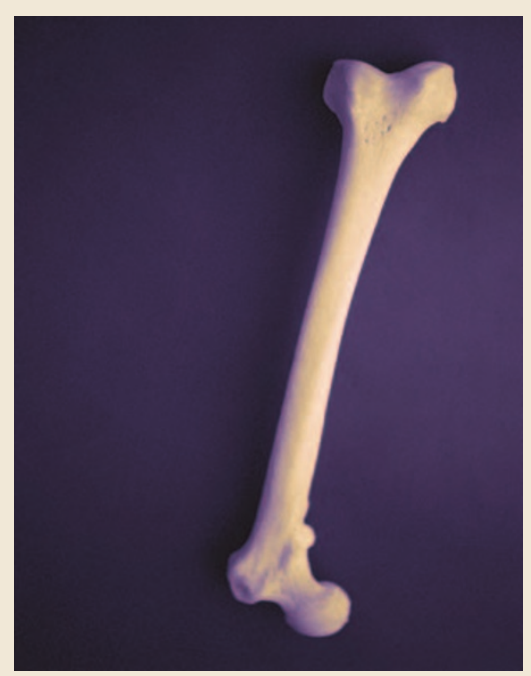

\section{Cycles and seizures}

Reporting in Nature Neuroscience, Maguire and colleagues show that cyclic alterations in the levels of steroid hormones during the oestrus cycle in mice are associated with changes in the subunit composition of $\mathrm{GABA}_{\mathrm{A}}(\gamma$-aminobutyric acid type $A$ ) receptors $\left(G_{A B A} R s\right)$, and that these alterations seem to be responsible for periodic changes in seizure susceptibility and anxiety.

$\mathrm{GABA}_{\mathrm{A}}$ Rs that contain $\delta$-subunits $\left(\delta \mathrm{GABA}_{\mathrm{A}} \mathrm{Rs}\right)$ mediate tonic inhibition in many neurons, including dentate gyrus granule cells,

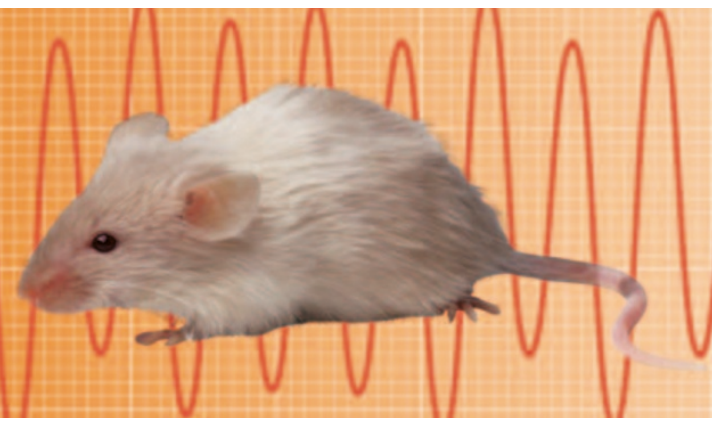

and are sensitive to neurosteroids. Using western blot analysis, Maguire et al. found that the expression of $\delta \mathrm{GABA}_{\mathrm{A}} \mathrm{Rs}$ in the hippocampus was much higher during late dioestrus, when progesterone concentrations are high, than during oestrus, when circulating progesterone is lower.

Consistent with the modifications of receptor subunit composition, granule cells from the dentate gyrus showed a twofold higher tonic conductance during late dioestrus than during oestrus. However, synaptic GABA ${ }_{A}$ f function, as measured by spontaneous inhibitory postsynaptic potentials, did not change across the oestrus cycle.

Female mice are relatively resistant to seizures induced by kainic acid during dioestrus compared with oestrus, and are also more anxious during oestrus. To show a link between the reorganization of $\mathrm{GABA}_{\mathrm{A}}$ Rs and seizure susceptibility, the authors used mice in which $\delta \mathrm{GABA}_{\mathrm{A}} \mathrm{R}$ expression was reduced by antisense mRNA or abolished by gene knockout. When antisense mRNA was used to prevent the normal upregulation of $\delta \mathrm{GABA}_{\mathrm{A}}$ Rs during late dioestrus, the tonic inhibitory current was not increased, and seizure susceptibility increased to a degree similar to that found during oestrus.

Consistent with this finding, Gabrd-knockout mice, in which $\delta \mathrm{GABA}_{\mathrm{A}} \mathrm{R}$ expression is abolished, did not show the normal lowering of seizure susceptibility during dioestrus. These findings support the idea that the cyclical reorganization of $\mathrm{GABA}_{\mathrm{A}} \mathrm{R}$ subunit composition leads to alterations in neuronal excitability and susceptibility to seizures.

These findings have important clinical implications. In humans, hormonal changes during the ovarian cycle can be associated with clusters of seizures (catamenial epilepsy) or with increased anxiety (premenstrual dysphoric disorder). These symptoms might result, at least in part, from cyclical changes in $\delta \mathrm{GABA}_{\mathrm{A}} \mathrm{R}$ expression, and these receptor subunits could, therefore, be a therapeutic target.

Rachel Jones

\section{(2) References and links}

ORIGINAL RESEARCH PAPER Maguire, J. L. et al. Ovarian cycle-linked changes in $\mathrm{GABA}_{A}$ receptors mediating tonic inhibition alter seizure susceptibility and anxiety. Nature Neurosci. 8, 797-804 (2005)

FURTHER READING Belelli, D. \& Lambert, J. L. Neurosteroids: endogenous regulators of the GABA receptor. Nature Rev. Neurosci. 6, 565-575 (2005) 